\title{
Diurnal Evolution and Annual Variability of Boundary-Layer Height and Its Correlation to Other Meteorological Variables in California's Central Valley
}

\author{
L. Bianco - I. V. Djalalova - C. W. King · J. M. Wilczak
}

Received: 24 September 2010 / Accepted: 7 May 2011 / Published online: 10 June 2011

(C) The Author(s) 2011. This article is published with open access at Springerlink.com

\begin{abstract}
One year of observations from a network of five 915-MHz boundary-layer radar wind profilers equipped with radio acoustic sounding systems located in California's Central Valley are used to investigate the annual variability of convective boundary-layer depth and its correlation to meteorological parameters and conditions. Results from the analysis show that at four of the sites, the boundary-layer height reaches its maximum in the late-spring months then surprisingly decreases during the summer months, with mean July depths almost identical to those for December. The temporal decrease in boundary-layer depth, as well as its spatial variation, is found to be consistent with the nocturnal low-level lapse rate observed at each site. Multiple forcing mechanisms that could explain the unexpected seasonal behaviour of boundary-layer depth are investigated, including solar radiation, precipitation, boundary-layer mesoscale convergence, low-level cold-air advection, local surface characteristics and irrigation patterns and synoptic-scale subsidence. Variations in solar radiation, precipitation and synoptic-scale subsidence do not explain the shallow summertime convective boundary-layer depths observed. Topographically forced cold-air advection and local land-use characteristics can help explain the shallow CBL depths at the four sites, while topographically forced low-level convergence helps maintain larger CBL depths at the fifth site near the southern end of the valley.
\end{abstract}

Keywords Boundary-layer height · California Central Valley · Convective boundary layer $\cdot$ Radar wind profiler

L. Bianco · I. V. Djalalova

University of Colorado Cooperative Institute for Research in the Environmental Sciences,

Boulder, CO, USA

L. Bianco $(\varangle) \cdot$ I. V. Djalalova · C. W. King $\cdot$ J. M. Wilczak

National Oceanic and Atmospheric Administration/Earth Systems Research Laboratory, 325 Broadway,

mailstop: PSD3, Boulder, CO 80305, USA

e-mail: Laura.Bianco@noaa.gov 


\section{Introduction}

The height of the convective boundary layer (CBL) has always been recognized as a parameter strongly dependent on several meteorological factors influenced by land-surface characteristics, synoptic horizontal wind convergence and divergence, mesoscale motions, such as upslope and downslope flows driven by topography, and low-level sea/land breezes. These forcings considerably affect turbulence development that generates the vertical transport of momentum, heat and moisture in the CBL (Stull 1988) and, consequently, the growth of the CBL. The magnitude of these fluxes strongly depends on the temperature and moisture states of both the surface and the atmosphere. Knowledge of what part of the total available energy in the atmosphere is available to generate turbulence is of fundamental importance to fully predict the development of the CBL.

In their study, King et al. (2006) noted that two Antarctic research stations, even if lying at similar latitudes and being subject to a similar diurnal variation of solar radiation at the top of the atmosphere, showed a greatly different response of the atmospheric boundary layer to the diurnally varying surface forcing. When they analyzed the summertime surface energy budget for both stations, they found that the main reason for the different diurnal variability at the two sites was the greater partitioning of available energy into latent heat fluxes at one of the sites. Recently, Endo et al. (2008) analyzed the characteristics of the CBL over a humid terrestrial area, finding a large contribution of moisture to the buoyancy affecting boundary-layer development in these conditions. Similar results were found by Tanaka et al. (2007) who investigated the relationship between surface conditions and atmospheric boundary-layer processes. These two last studies were conducted using CBL depth estimates obtained by radar wind profilers on selected days and co-located surface-layer observations.

Radar wind profilers, among other remote sensing instruments used to monitor the height of the CBL, have the advantage of providing direct and continuous observations of the boundary layer over long periods of time. In this study, we analyze a one-year period of observations obtained by $915-\mathrm{MHz}$ radar wind profilers and associated Radio Acoustic Sounding Systems (RASS) at five sites within California's Central Valley. We first document the seasonal variability of boundary-layer structure, including CBL depth, wind speed and temperature. We then investigate CBL forcing mechanisms, including solar radiation, precipitation, lapse rate, temperature advection, mesoscale convergence, land-surface characteristics including irrigation patterns and synoptic-scale subsidence.

The article is organized as follows: the measurement sites, the area of interest, the instruments and the data used in this study are introduced in Sect. 2; the seasonal variability of boundary-layer structure is presented in Sect. 3; CBL depth forcing mechanisms are investigated in Sect. 4; and conclusions are summarized in Sect. 5.

\section{Measurement Sites, Area of Interest, Instruments and Data}

\subsection{Measurement Sites and Area of Interest}

California's Central Valley has been chosen as the region of focus for this study, where five sites with almost continuous measurements over a period of one year were available. A map showing the location of these sites and the terrain of the area is presented in Fig. 1.

California's Central Valley is approximately $800 \mathrm{~km}$ long, with the northern half referred to as the Sacramento Valley and the southern half as the San Joaquin Valley. The two halves 


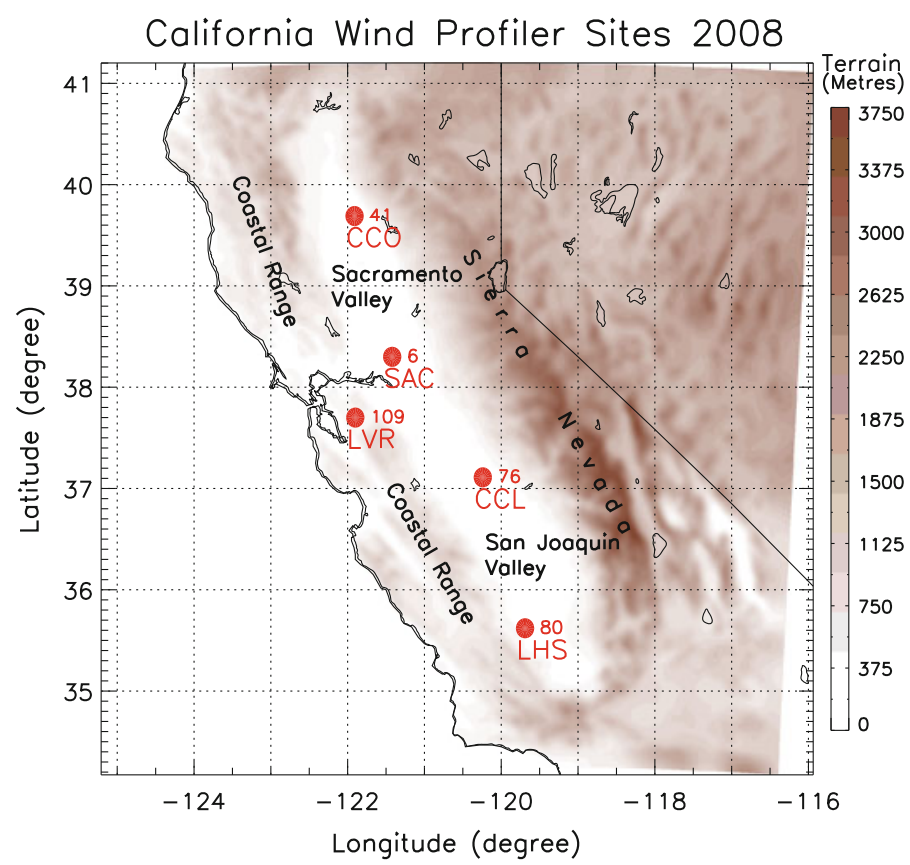

Fig. 1 Geographical locations of the five sites, their altitude (in metres) and the terrain of the area examined in this study

join in the Delta Region, east of San Francisco. The Central Valley is bordered by the Coastal Range Mountains to the west, which lie parallel to the Pacific coastline and the Sierra Nevada on the eastern side of the valley. The Delta Region is at or below sea level and the valley slopes slightly upward to about $100 \mathrm{~m}$ above sea level (a.s.l.) at the city of Red Bluff on the northern end of the valley and $125 \mathrm{~m}$ at the city of Bakersfield on the southern end. The topography is of critical importance to the airflow pattern present in the valley. According to previous studies (Schultz et al. 1961; Frenzel 1962; Hays et al. 1984; Moore et al. 1987; Zaremba and Carroll 1999; Zhong et al. 2004), the prevailing summertime wind pattern is dominated by a flow of marine air into the Central Valley through a gap in the Coastal Range east of the San Francisco Bay Area. This flow moves into the Delta Region and splits into two currents curving north into the Sacramento Valley and south into the San Joaquin Valley. A wind vector investigation for the sites analyzed here (shown later) corroborates these previous studies. In addition, a thermally driven circulation, deriving from anabatic and katabatic flows along the mountain slopes surrounding the valley, is superimposed on this pattern.

The sites of interest for our study, introduced from north to south, are:

(1) CCO: Chico $(39.70 \mathrm{~N}, 121.91 \mathrm{~W}, 41 \mathrm{~m}$ a.s.l.). The profiler site is $10 \mathrm{~km}$ south-west of the city of Chico, with irrigated orchards and fields surrounding the site to at least a 10-km radius.

(2) SAC: Sacramento $(38.30 \mathrm{~N}, 121.42 \mathrm{~W}, 6 \mathrm{~m}$ a.s.1.). The site is located $70 \mathrm{~km}$ south of downtown Sacramento, just east of the Delta Region, with the Sacramento Valley to the north and the San Joaquin Valley to the south. The site is in a heavily agricultural region, with irrigated fields to at least $10 \mathrm{~km}$ distance in all directions. 
(3) LVR: Livermore $(37.71 \mathrm{~N}, 121.90 \mathrm{~W}, 108 \mathrm{~m}$ a.s.1.). The site is located in the foothills of the Coastal Range Mountains, midway between the San Francisco Bay to the west and the northern San Joaquin Valley to the east. The site is $10 \mathrm{~km}$ west of the city of Livermore, in a fairly heavily urbanized area. There is no significant agricultural land in the region although non-irrigated grass fields represent about $50 \%$ of the land use in the area.

(4) CCL: Chowchilla $(37.11 \mathrm{~N}, 120.24 \mathrm{~W}, 76 \mathrm{~m}$ a.s.l.). The site is located in the east-central San Joaquin Valley on the east side of the city of Chowchilla. Irrigated fields and orchards surround the site to at least a $15 \mathrm{~km}$ distance.

(5) LHS: Lost Hills $(35.62 \mathrm{~N}, 119.69 \mathrm{~W}, 87 \mathrm{~m}$ a.s.1.). The site is located in the south-western San Joaquin Valley at the Lost Hills Airport, on the east side of the city of Lost Hills. Only approximately $30 \%$ of the land area within a $15-\mathrm{km}$ radius is irrigated orchards, with the remainder being natural grass areas.

All sites have radar wind profilers equipped with RASS measurements available for all of 2008, except for Sacramento, where the radar wind profiler-RASS is only available until the end of July. Nevertheless, we still include this site in our analysis.

\subsection{Instruments and Data}

\subsubsection{Radar Wind Profilers}

The height of the CBL was measured using 915-MHz radar wind profilers. For this type of instrument, the backscattered electromagnetic signal in clear air is generated by fluctuations in the water vapour and temperature fields of the atmosphere (Ochs and Lawrence 1972; Wesely 1976; Wyngaard and LeMone 1980). White et al. (1991) have shown that the backscattered signal is proportional to the enhancement in the radar reflectivity that is directly related to the atmospheric refractive index structure parameter, $C_{n}^{2}$. Regions of strong signal return are associated with the elevated inversion that caps the CBL. White (1993) determined the evolution of the CBL by looking for the height of the peak in the signal-to-noise ratio (and hence $C_{n}^{2}$ ) in the hourly vertical profiles. In our study, hourly convective boundary-layer heights were calculated using the automated objective algorithm of Bianco et al. (2008). This technique incorporates information on the returned signal strength (signal-to-noise ratio), vertical velocity variance and spectral width of the vertical velocity. Thus, the definition of the CBL used in the present analysis is the lowest layer of the atmosphere that is in contact with the surface and is continuously turbulent. The automated hourly CBL depth values were also visually edited to eliminate potential outliers.

The radar wind profiler data used here have two vertical resolutions, high resolution (covering the part of the atmosphere from $\approx 130 \mathrm{~m}$ up to $\approx 2,400 \mathrm{~m}$ above ground level, a.g.l.) and low resolution (covering the part of the atmosphere from $\approx 150 \mathrm{~m}$ up to $\approx 4,000 \mathrm{~m}$ a.g.l.). The different operational specifications used for the various radar wind profilers are summarized in Table 1. For the computation of boundary-layer height, we used high-resolution data because, in this specific case, they cover the entire part of the lower atmosphere in which the boundary layer is found. However, in the analysis of wind velocity data, both resolutions were used. Specifically the high resolution data were used up to $500 \mathrm{~m}$ a.g.l. and the low resolution data above this level, so that observations were nearly always available between $\approx 150 \mathrm{~m}$ and $\approx 2,000 \mathrm{~m}$ a.g.l. This technique is applied to the data from all sites.

All consensus wind data were quality controlled. This quality control includes both automated and manual checks of the wind-speed values, to detect unusually strong winds or 
Table 1 Operational specification for the radar wind profilers

\begin{tabular}{llllllll}
\hline Site & \multicolumn{2}{l}{ High resolution specifications } & & \multicolumn{2}{l}{ Low resolution specifications } \\
\cline { 2 - 3 } & 1st height $(\mathrm{m})$ & Gate spacing $(\mathrm{m})$ & No. of gates & & 1st height $(\mathrm{m})$ & Gate spacing $(\mathrm{m})$ & No. of gates \\
\hline CCO & 127 & 60 & 38 & 135 & 105 & 38 \\
SAC & 137 & 55 & 25 & 199 & 96 & 37 \\
LVR & 120 & 60 & 38 & 131 & 96 & 38 \\
CCL & 142 & 60 & 38 & 150 & 105 & 38 \\
LHS & 127 & 60 & 38 & 135 & 105 & 36 \\
\hline
\end{tabular}

outliers. Data for the six months of April-September have also been inspected for contamination from migrating birds (Wilczak et al. 1995) by visual examination of signal-to-noise ratio, spectral width and wind-vector daily plots. Overall, the percentage of good hourly data on an annual basis for each site in the first $2 \mathrm{~km}$ of the boundary layer were $\mathrm{CCO}=83.7 \%$, $\mathrm{SAC}=81.1 \%, \mathrm{LVR}=87.2 \%, \mathrm{CCL}=88.3 \%$ and $\mathrm{LHS}=94.6 \%$.

\subsubsection{RASS}

The remote measurement of temperature in the lower atmosphere has been achieved with the use of a radio acoustic sounding system co-located with the radar wind profilers, through which a longitudinal acoustic wave propagates upward in the air as a local compression and rarefaction of the ambient air. These density variations cause a corresponding variation in the local refractive index of the atmosphere, tracked by the Doppler radar through the reflection of a small amount of the electromagnetic energy as it propagates through the acoustic pulse. RASS is hence used to measure the speed of sound at various heights above the ground. From the measure of the speed of sound, the sonic temperature is derived, which is very nearly equal to the virtual temperature (May et al. 1990).

Operational specifications for the RASS measurements are the same as for the high resolution mode for each radar wind profiler. The maximum height of the RASS signal is determined not only by the radar wavelength but also by the temperature and moisture structure of the atmosphere and by the fact that horizontal wind could transport acoustic waves outside of the electromagnetic beams. For typical mid-latitude conditions, a 915-MHz profiler-RASS system usually provides temperature measurements up to $1 \mathrm{~km}$. In a moist boundary layer the maximum height is generally above $1 \mathrm{~km}$ (Wilczak et al. 1996).

\subsubsection{Surface Sensors}

Surface meteorological variables for three sites, Chowchilla, Chico and Lost Hills, were collected by instrument stations co-located with the radar wind profiler-RASS, over the 1 -year analysis period. Each tower sampled the standard meteorological parameters making available hourly values of 2-m temperature and relative humidity, 10-m wind speed, wind direction, atmospheric pressure, solar and net radiation and precipitation. Solar radiation was measured with Kipp and Zonen CM3 pyranometers. Direct measurements of the surface fluxes of momentum, heat and moisture were not available. For the Livermore and Sacramento sites, we used the geographically closest Automated Surface Observing System (ASOS) stations. For the Livermore site, this was Livermore Municipal Airport (37.694N, 
$121.817 \mathrm{~W}, 121 \mathrm{~m}$ a.s.1.), roughly $7.5 \mathrm{~km}$ from the wind profiler site, and for the Sacramento site, we used the ASOS station at the Sacramento Executive Airport (38.513N, 121.493W, $7.6 \mathrm{~m}$ a.s.1.), $24 \mathrm{~km}$ from the wind profiler site.

\section{Annual Variability of CBL Depth and Vertical Structure}

Time series of the daily maximum CBL depth, as a function of month of the year, are presented in Fig. 2 for the five sites, showing both individual daily values and a smoothed 5-day running mean. For each site, in January, the smoothed CBL depth is at or near its minimum, then increases with time through the spring reaching maximum values during the months of April or May. For all sites except Lost Hills, the daily maximum CBL depth then decreases rapidly to significantly lower values for the months of June, July and August. The CBL depths partially recover to a second but lower set of peaks in early autumn, then decrease again heading into the winter months.
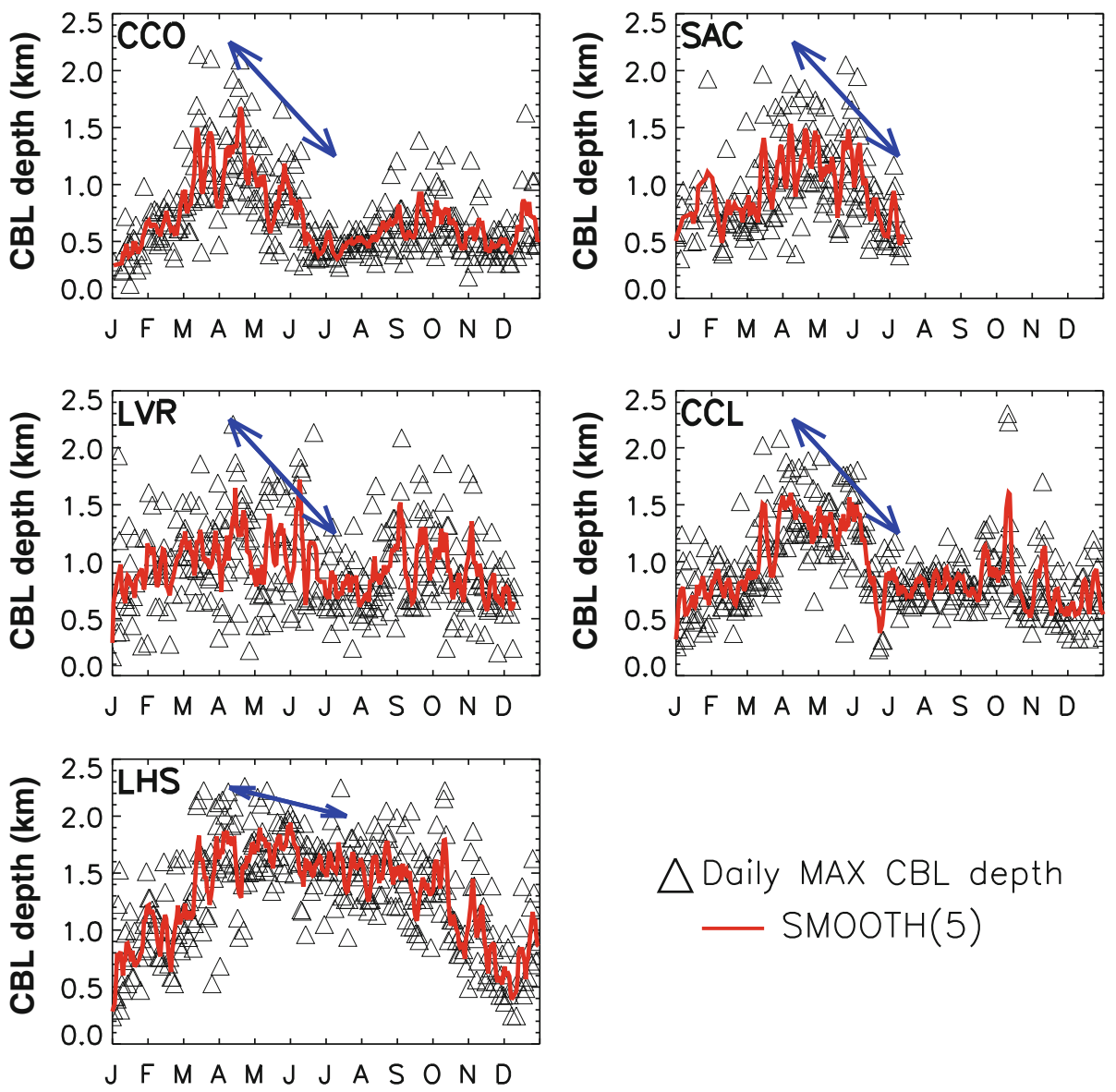

\section{$\triangle$ Daily MAX CBL depth SMOOTH(5)}

Fig. 2 Time series of maximum daily boundary-layer depths $(\mathrm{km})$ as a function of the period of the year for the five sites (black triangles). In red, a smoothed interpolation of the data. Blue arrows are a schematic representation of the decrease of boundary-layer depths during the summer months. The $x$-axis is time (months of the year); the $y$-axis is height $(\mathrm{km})$ 


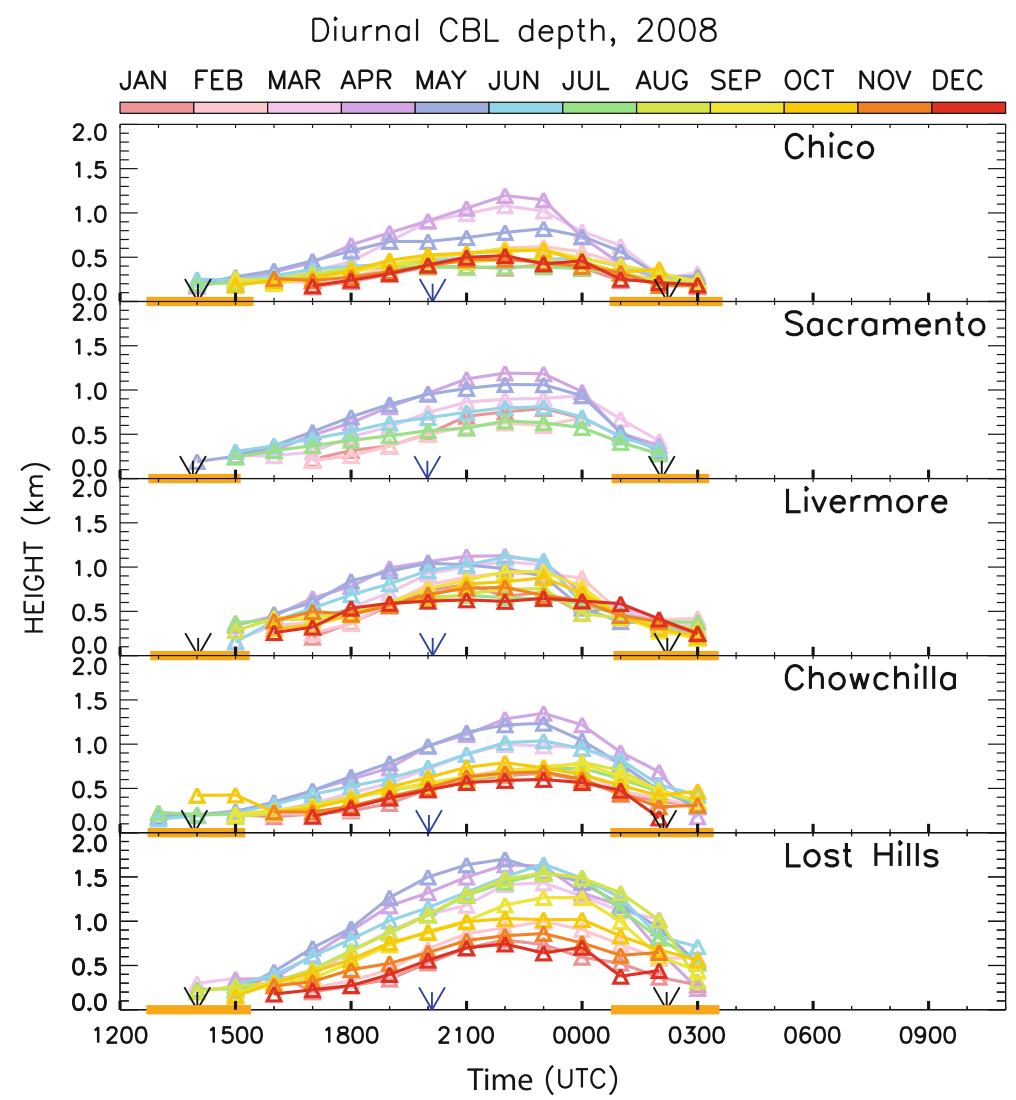

Fig. 3 Monthly-averaged diurnal boundary-layer cycle for the five sites. Blue arrows on the $x$-axis indicate solar noon, while black arrows indicate averaged values of sunrise and sunset. The orange bars on the $x$-axis denote the entire set of values of sunrise and sunset for all the months of the year

It is interesting to note that the maximum values of the CBL do not correspond to the warmest summer months, but occur much earlier at all of the sites. For the Sacramento site, even though the time series is interrupted at the end of July, we observe much higher values of the CBL in April and May compared to June and July. The only site that does not show the abrupt decrease of boundary-layer depths for the summer months of July and August is Lost Hills. Still, CBL depths at Lost Hills are the highest during the spring months, followed by a slow but steady decrease through the remainder of the summer and then followed by a more rapid decrease in the autumn months.

Figure 3 shows the monthly-averaged diurnal boundary-layer cycle for the five sites. Sunrise and sunset are indicated by black arrows, and solar noon is indicated by blue arrows. For most sites, the months of March, April and May have the longest and deepest daily cycle of CBL depths. Surprisingly, at Chico, Chowchilla and Livermore, the July and August diurnal CBL traces are almost identical to those in December.

To further illustrate the annual cycle of CBL structure, we show in Fig. 4, the diurnal CBL evolution for the Chowchilla site averaged for each month of the year (black triangles) together with the vertical distribution of the diurnal monthly-averaged wind speed. The monthly-averaged diurnal wind speeds show weaker values as the boundary layer grows in 
CCL
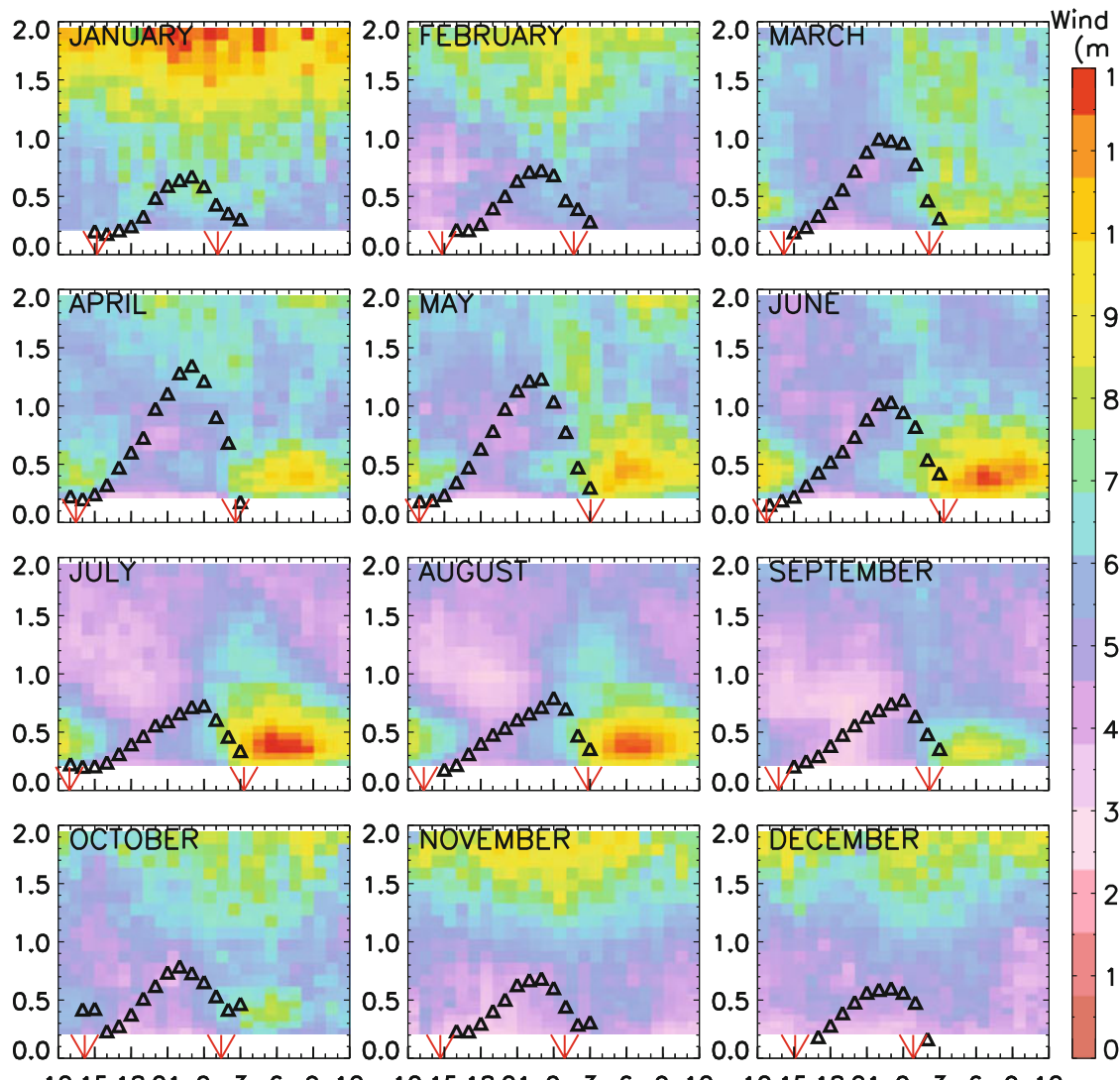

1215182100360912

Fig. 4 Chowchilla site. Black triangles CBL diurnal cycle averaged for each month of the year. In colour, vertical distribution of the diurnal monthly-averaged wind speed. The $x$-axis is time (UTC); $y$-axis is height (km). Red arrows on the $x$-axis denote the sunrise and sunset

the morning through mid-afternoon hours of the day (1600-2300 UTC or 0800-1500 LT). During the summer months, stronger winds associated with a nocturnal low-level jet (LLJ) occur at or below $500 \mathrm{~m}$, soon after the collapse of the boundary layer (0300-1100 UTC or 1900-0300 LT). This is in accordance with previous studies (Burk and Thompson 1996; Bao et al. 2008). The LLJ begins in March-April and continues through the summer until September-October, with the height of the jet maximum near $400 \mathrm{~m}$ a.g.l., with little hourly variation in the jet height during the night, or from month to month. The jet reaches a maximum mean speed of nearly $12 \mathrm{~m} \mathrm{~s}^{-1}$ in July. The LLJ at the Livermore site (Fig. 5) is much weaker than at Chowchilla, and its vertical structure is more complex. Maximum speeds occur within the CBL during the late afternoon and early evening hours (0000-0500 UTC or 1600-2100 LT) as the CBL is collapsing. In July, and to a lesser extent in August, an elevated, secondary local maximum occurs near $1.0 \mathrm{~km}$ a.g.l., well above the daytime maximum height the CBL. This could be due to the location of this site, which is situated relatively close to the ocean in a gap between the San Francisco Bay Area and the Central Valley where a thermally driven flow from the cool Pacific Ocean into the Central Valley (Bao et al. 2008; Zhong et al. 
LVR
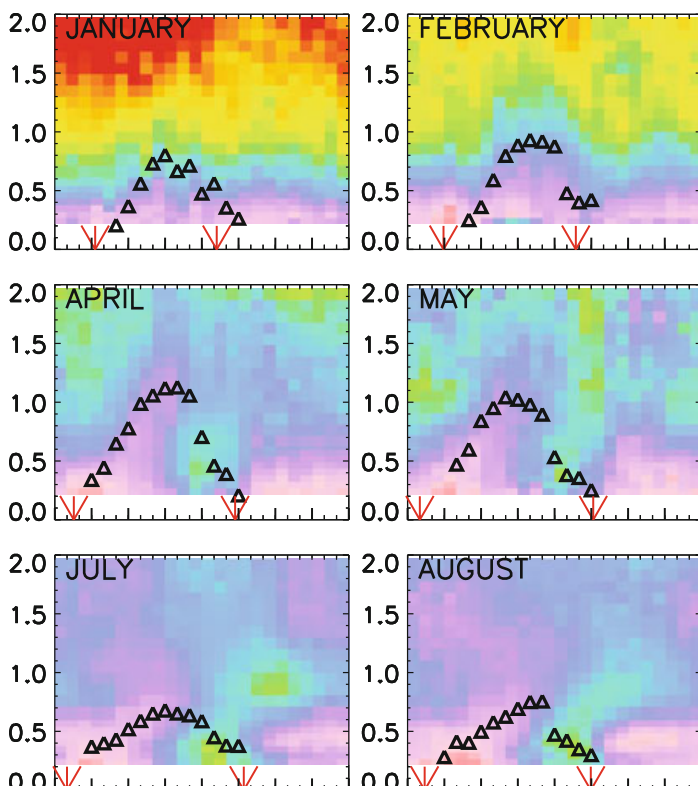

2.0 OCTOBER
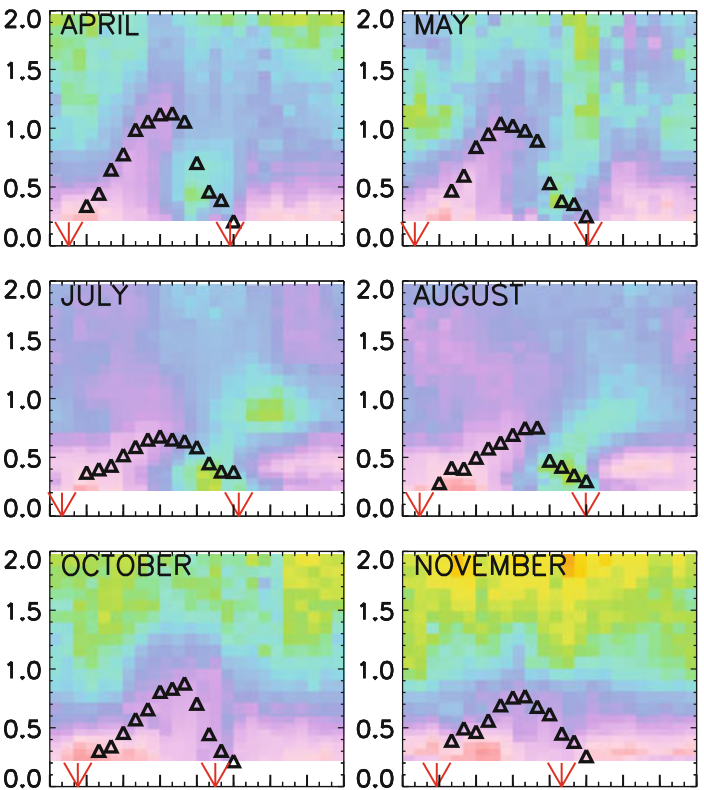

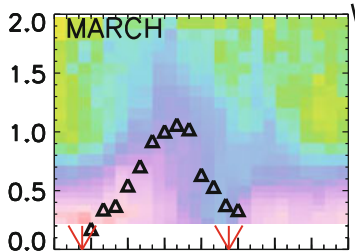

Wind speed
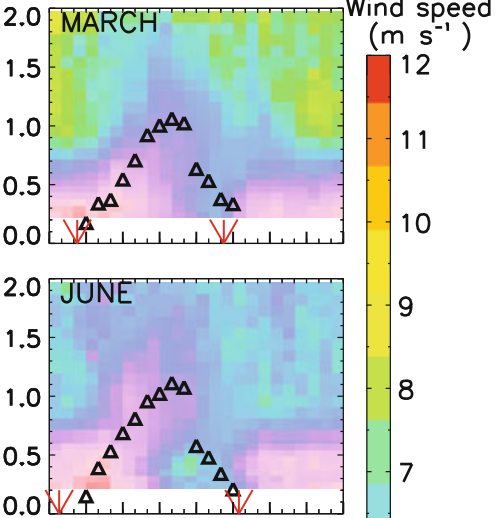

9

8

7

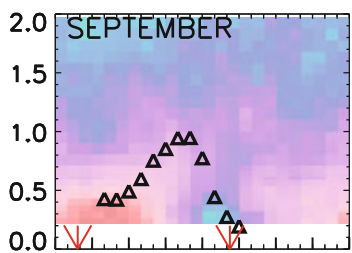

6

5

4

3

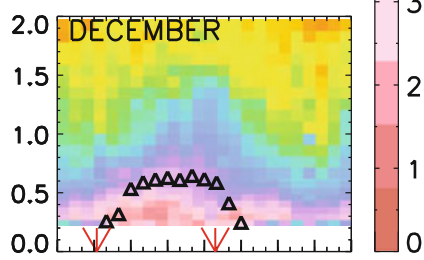

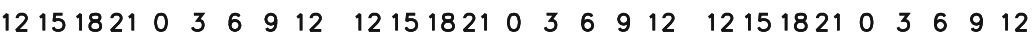

Fig. 5 Same as in Fig. 4, but for the Livermore site

2004) is channelled. Lost Hills, shown in Fig. 6, is the only site showing a different CBL depth behaviour, with the CBL depths having almost the same maximum value through the entire period between April and August. Here, the LLJ is still considerable in May and June, but its intensity is weaker compared to Chowchilla and Chico, and its maximum speeds are more variable both from hour to hour and month to month.

For all the three sites, we note that the collapse of the CBL can take a surprisingly long period of time, with the peak CBL depth occurring up to $3-5 \mathrm{~h}$ before sunset (sunrise and sunset are indicated by red arrows in the figures) followed by a steady decrease in CBL depth. By the time sunset has occurred, the CBL most often, has collapsed to be at or near its minimum observed value. Other interesting features are observed by superimposing the daily cycle of CBL depth with the virtual potential temperature measured by the RASS. Figure 7 compares the vertical distribution of the monthly-averaged diurnal virtual potential temperature with the daily cycle of the monthly-averaged CBL depth in km (black triangles) for the Chowchilla site (all sites except Lost Hills show similar behaviour). Green coloured numbers, located at the upper right corner of each month, represent the monthly accumulated precipitation in $\mathrm{mm}$. 


\section{LHS}
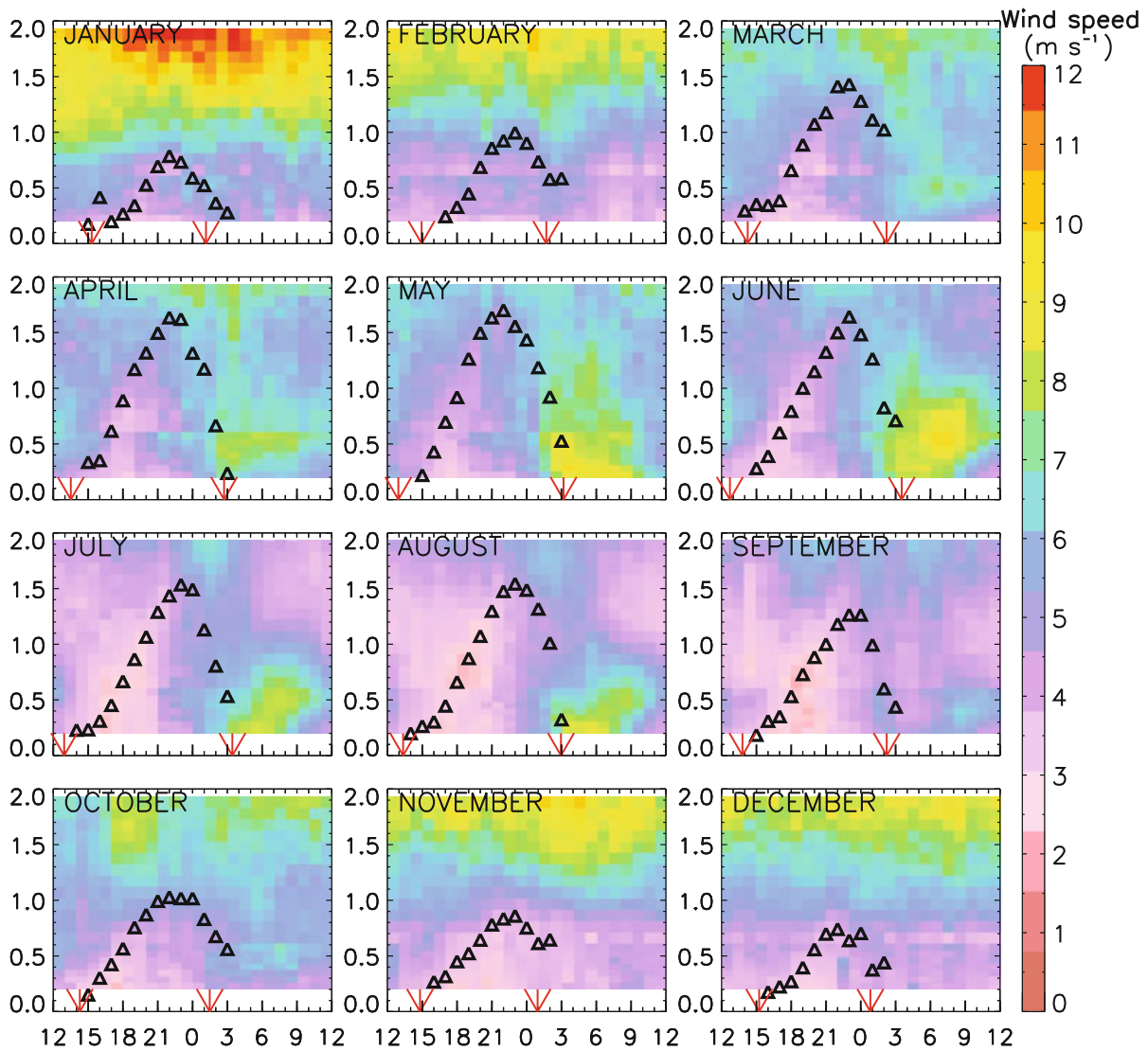

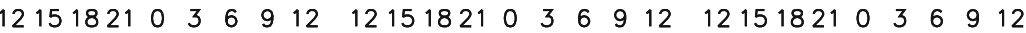

Fig. 6 Same as in Fig. 4, but for the Lost Hills site

The maximum height reached by the RASS is around or slightly above $1 \mathrm{~km}$, which is sufficient to depict most of the CBL. The daily cycles of the CBL depth and virtual potential temperature indicate that the peak boundary-layer temperatures occur after the maximum CBL depth is achieved. The warmest months are those from June to September, with virtual temperatures inside the $\mathrm{CBL}$ near $34-38^{\circ} \mathrm{C}$. However, for these months the maximum value of mean boundary-layer depth is much lower than those observed in April and May, even though the virtual potential temperature inside the $\mathrm{CBL}$ is much higher.

\section{CBL Depth Forcing Mechanisms}

\subsection{Surface Solar Radiation and Precipitation}

Surface solar radiation is the defining mechanism for driving the CBL, and variations due to clouds or aerosols can have a pronounced effect on CBL depth. Three of the wind profiler sites had co-located solar radiation measurements, as discussed in Sect. 2. Table 2 contains 

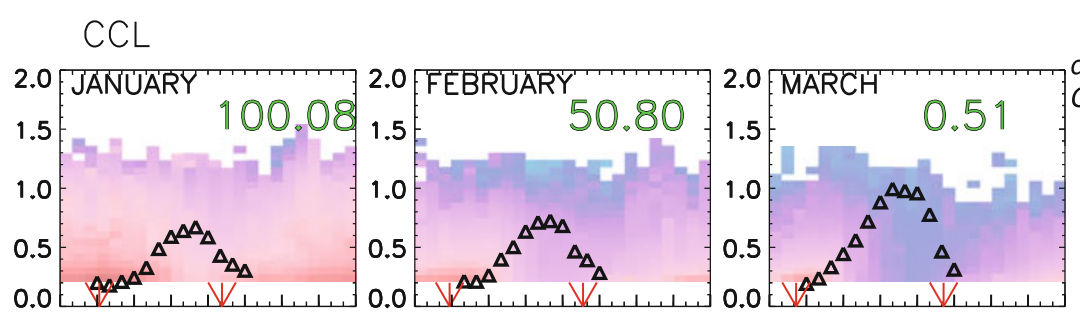

degrees
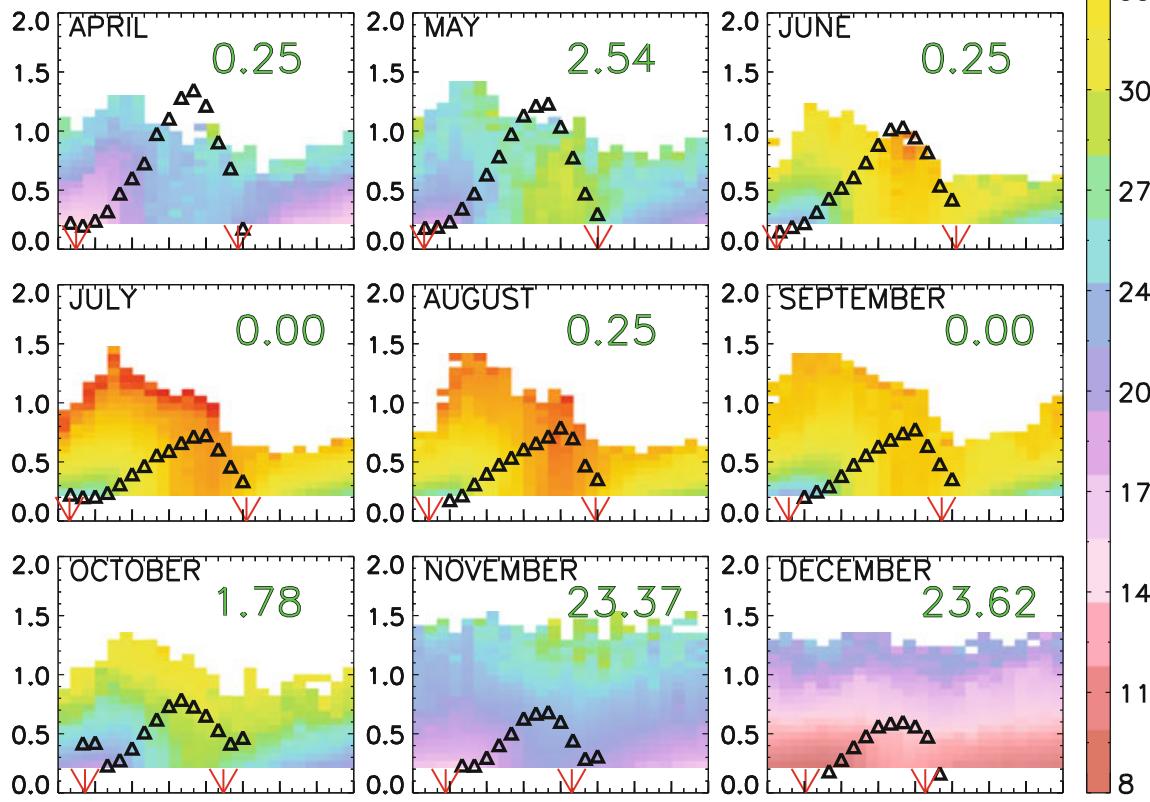

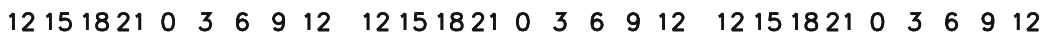

Fig. 7 Chowchilla site. Black triangles CBL diurnal cycle averaged for each month of the year. In colour, vertical distribution of the diurnal monthly-averaged virtual potential temperature. The $x$-axis is time (UTC); $y$-axis is height $(\mathrm{km})$. Red arrows on the $x$-axis denote the sunrise and sunset. Green numbers are monthly accumulated precipitation in $\mathrm{mm}$. A minimum of $15 \%$ of the observations possible in a month are required to show a RASS value

monthly means of the daily maxima solar radiation $\left(\mathrm{W} \mathrm{m}^{-2}\right)$ and of the daily integrated solar radiation $\left(\mathrm{W} \mathrm{h} \mathrm{m}^{-2}\right)$ at the Chico, Chowchilla and Lost Hills sites. Overall, the large values of both solar radiation measures for the summer months are indicative of mostly cloud-free conditions.

The largest monthly-averaged maximum CBL depths at Chico and Chowchilla were previously found to occur in April with values of approximately 1.4 and $1.3 \mathrm{~km}$, respectively (Fig. 3), decreasing to 0.7 and $0.5 \mathrm{~km}$ in July. However, as shown in Table 2, both the daily maxima and integrated solar radiation for these two sites are considerably larger in July than in April and therefore cannot explain the decrease in CBL depths from April to July. Furthermore, the July value of integrated solar radiation at Chico is only $8 \%$ greater than the value for Lost Hills, and the Chowchilla value is almost identical to that for Lost Hills. Solar radiation therefore also cannot explain the lower July CBL depths at Chico and Chowchilla relative to Lost Hills. 
Table 2 Monthly mean hourly maximum solar radiation, $S R$ (top number); and monthly mean daily-integrated solar radiation (bottom number)

\begin{tabular}{lrrrrrrrrrrrr}
\hline Site & Jan & Feb & Mar & Apr & May & Jun & Jul & Aug & Sep & Oct & Nov & Dec \\
\hline CCO & & & & & & & & & & & & \\
Max $S R\left(\mathrm{~W} \mathrm{~m}^{-2}\right)$ & 279 & 493 & 707 & 850 & 856 & 926 & 886 & 895 & 766 & 581 & 402 & 323 \\
Total $S R\left(\mathrm{~W} \mathrm{~h} \mathrm{~m}^{-2}\right)$ & 1,614 & 3,125 & 4,892 & 6,624 & 7,265 & 7,897 & 7,092 & 7,065 & 5,670 & 3,862 & 2,388 & 1,783 \\
CCL & & & & & & & & & & & & \\
Max $S R\left(\mathrm{~W} \mathrm{~m}^{-2}\right)$ & 324 & 580 & 791 & 894 & 885 & 986 & 923 & 886 & 804 & 636 & 466 & 325 \\
Total $S R\left(\mathrm{~W} \mathrm{~h} \mathrm{~m}^{-2}\right)$ & 1,920 & 3,583 & 5,561 & 6,892 & 7,381 & 8,366 & 7,741 & 7,125 & 5,962 & 4,339 & 2,774 & 1,825 \\
LHS & & & & & & & & & & & & \\
Max $S R\left(\mathrm{~W} \mathrm{~m}^{-2}\right)$ & 412 & 638 & 855 & 941 & 921 & 982 & 946 & 925 & 845 & 703 & 492 & 377 \\
Total $S R\left(\mathrm{~W} \mathrm{~h} \mathrm{~m}^{-2}\right)$ & 2,358 & 4,062 & 5,938 & 7,292 & 7,567 & 8,297 & 7,740 & 7,320 & 6,242 & 4,626 & 2,960 & 2,066 \\
\hline
\end{tabular}

An annual histogram of monthly accumulated precipitation data is shown in Fig. 8. The red box in the figure outlines the dry-season months from March to September, during which less than $10 \mathrm{~mm}$ of precipitation fell at each of the five sites. Variations in precipitation clearly cannot explain either the July decrease in CBL depths at Chico and Chowchilla relative to April, nor the lower July CBL depths at Chico and Chowchilla relative to Lost Hills. To avoid the influence from precipitation on soil moisture and CBL growth, further analysis is restricted to the dry months from April to September. March is excluded as it is a time of transition between the wet and dry seasons, when the soil moisture is decreasing.

\subsection{Lapse Rate}

The CBL depth daily cycle overlaid with the lapse rate of the virtual potential temperature $\left(\mathrm{K} \mathrm{km}^{-1}\right)$ measured by the RASS is shown in Fig. 9. Only the Chico and Lost Hills sites are presented here, as the other sites are very similar to Chico. Several features may be noted from this figure. First, the daily cycle of the boundary layer is clearly revealed from the lapse rate. Lapse rate values inside the CBL are nearly constant and nearly adiabatic, but positive in the nighttime and early morning hours due to radiational cooling at the earth's surface. For Chico, the virtual potential temperature lapse rate shows strong stratification during the nighttime hours, while Lost Hills is only weakly stratified. Second, for the summer months with shallow CBL depths (June through September), the Chico nighttime lapse rates are much greater than during April and May. In contrast, the Lost Hills virtual potential temperature lapse rate is not only much smaller during the nighttime hours, but its behaviour is almost the same for all months from April to September. As a result, the CBL at Lost Hills is able to grow to substantial depths during each of these months.

\subsection{Low-Level Mesoscale Convergence}

In Fig. 10, we plot the monthly-averaged wind vectors for every site, for the six driest months and over the first $500 \mathrm{~m}$ above the ground level. First, this figure shows the well documented pattern of flow moving into the Delta Region and splitting into two currents, one curving 


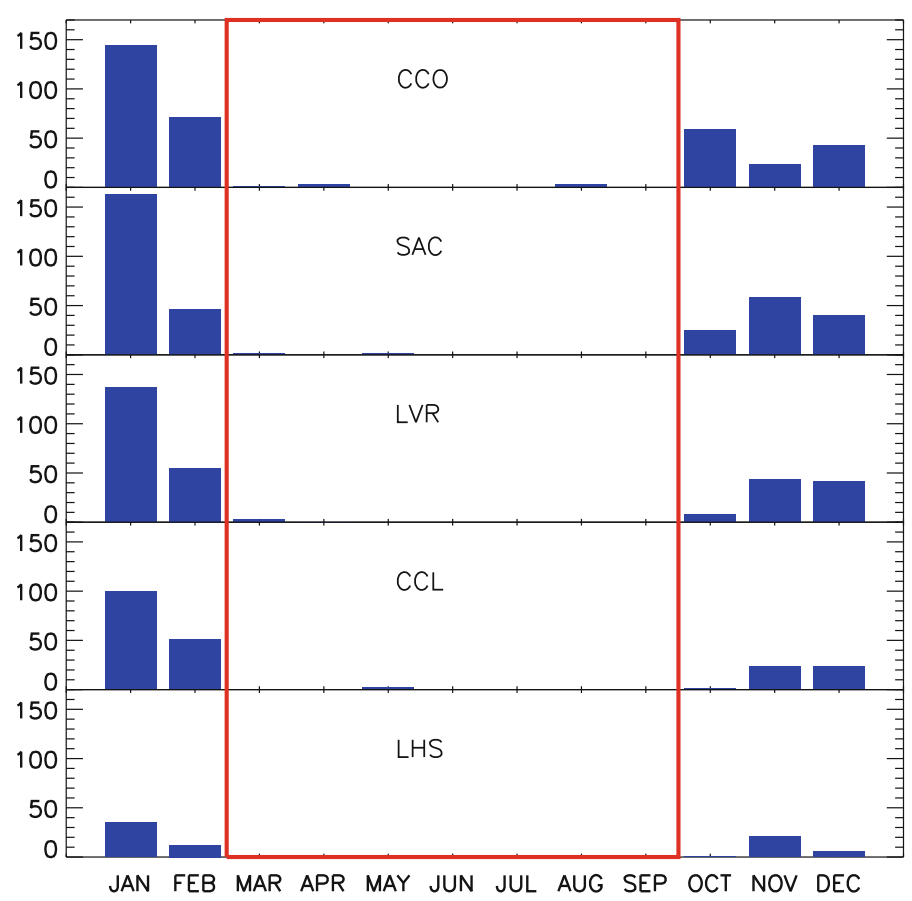

Fig. 8 Annual histogram of the monthly accumulated precipitation in $\mathrm{mm}$ for all the sites

north into the Sacramento Valley and one south into the San Joaquin Valley, as discussed in the previous studies introduced in Sect. 2.1. Secondly, the along-valley flow decelerates near the southern end of the valley, apparently due to blocking by the steep topography that closes off the valley. Values of the along-valley wind-speed difference between Chowchilla and Lost Hills peak in June-July and then decrease moderately in August, as shown in the lower panel of Fig. 10. If this speed difference can be interpreted as boundary-layer flow convergence, then it is consistent with the weaker lapse rates and greater boundarylayer depths at Lost Hills for summer months when the other sites show a decrease in CBL depths.

\subsection{Low-Level Temperature Advection}

Cold-air advection within the boundary layer can help reduce CBL depths by counter-acting the warming due to surface heating from solar radiation. Figure 11 shows temperature advection for both the Delta Region and the southern Central Valley. For the Delta Region (upper panels of Fig. 11), the advection is calculated as the difference in temperature between Livermore and the average temperature over the three inland sites of Chico, Sacramento and Chowchilla, multiplied by the westerly wind component at Livermore. Increased cold-air advection during the months of July and August is evident, especially at lower levels and afternoon to evening hours. The strongest cold-air advection for these summer months begins in the early afternoon hours (starting at about 2200 UTC, 1400 LT), after which the CBL rapidly decreases in depth. This cold-air advection is associated with the push of marine air into the Central Valley that occurs with the afternoon sea-breeze circulation. Low-level 


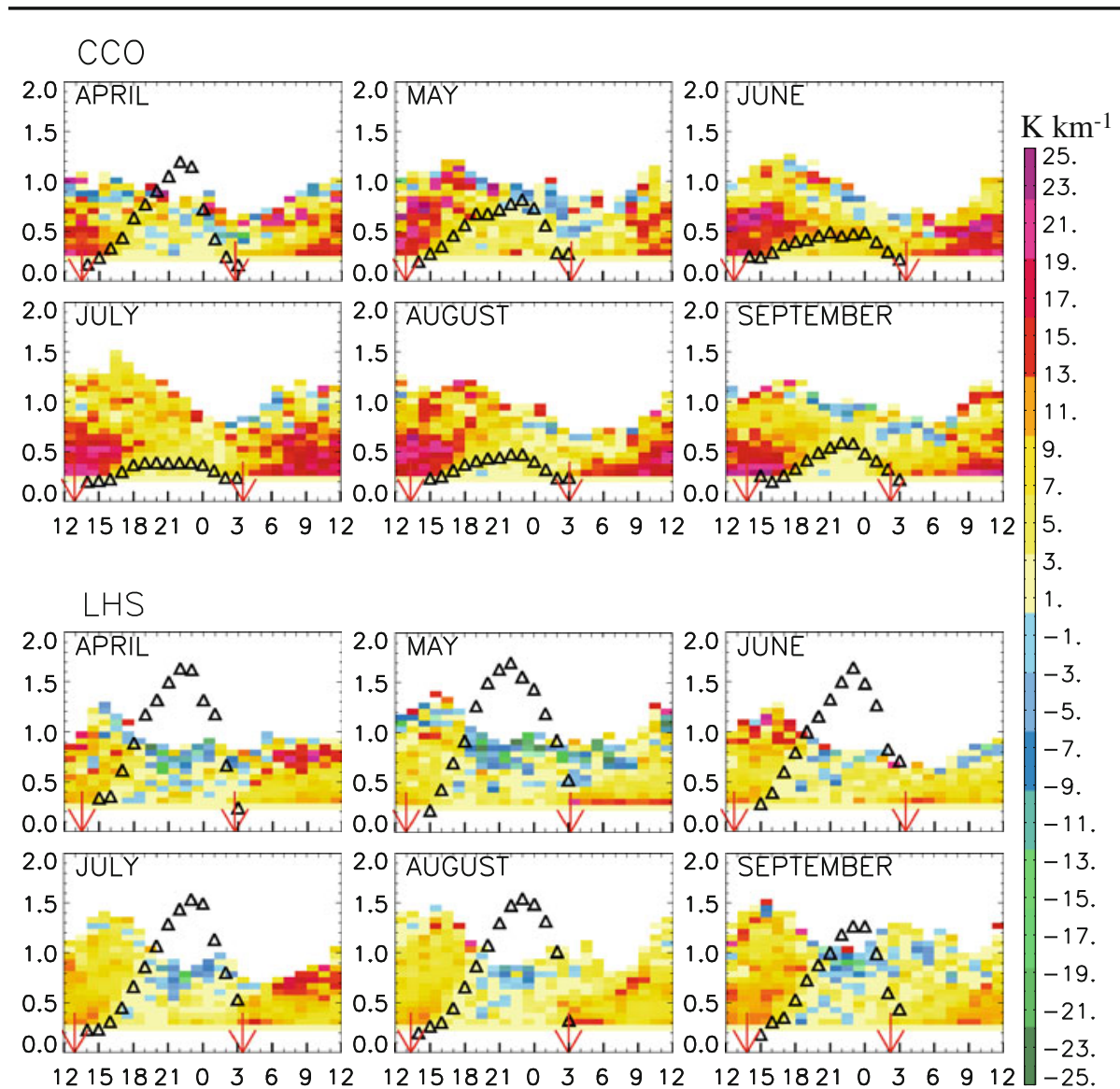

Fig. 9 Chico and lost Hills. Black triangles CBL diurnal cycle monthly-averaged for the six driest months of the year. In colour, vertical distribution of the diurnal monthly-averaged lapse rate of virtual potential temperature. Red arrows on the $x$-axis denote the sunrise and sunset. The $x$-axis is time (UTC); $y$-axis is height $(\mathrm{km})$

cold-air advection will increase the stratification and will counteract the warming due to solar insolation, and will contribute to the shallower CBL depths at Livermore, Sacramento, Chico and Chowchilla during summer months.

The lower panels of Fig. 11 show the temperature advection in the southern Central Valley computed by multiplying the along-valley wind component at Lost Hills by the difference between the temperature at Lost Hills and the temperature at Chowchilla. The cold-air advection is much smaller here than for Livermore, and is nearly the same for all months. This difference in cold-air advection will contribute to the smaller CBL depths for the more northern profiler sites during the summer months relative to the Lost Hill site.

\subsection{Land-Use Characteristics}

In this section, we investigate the relationship between boundary-layer depth and surface specific humidity and then investigate the role of land-use type including irrigation on the surface specific humidity. For each month at each of the five sites the diurnal variation of 

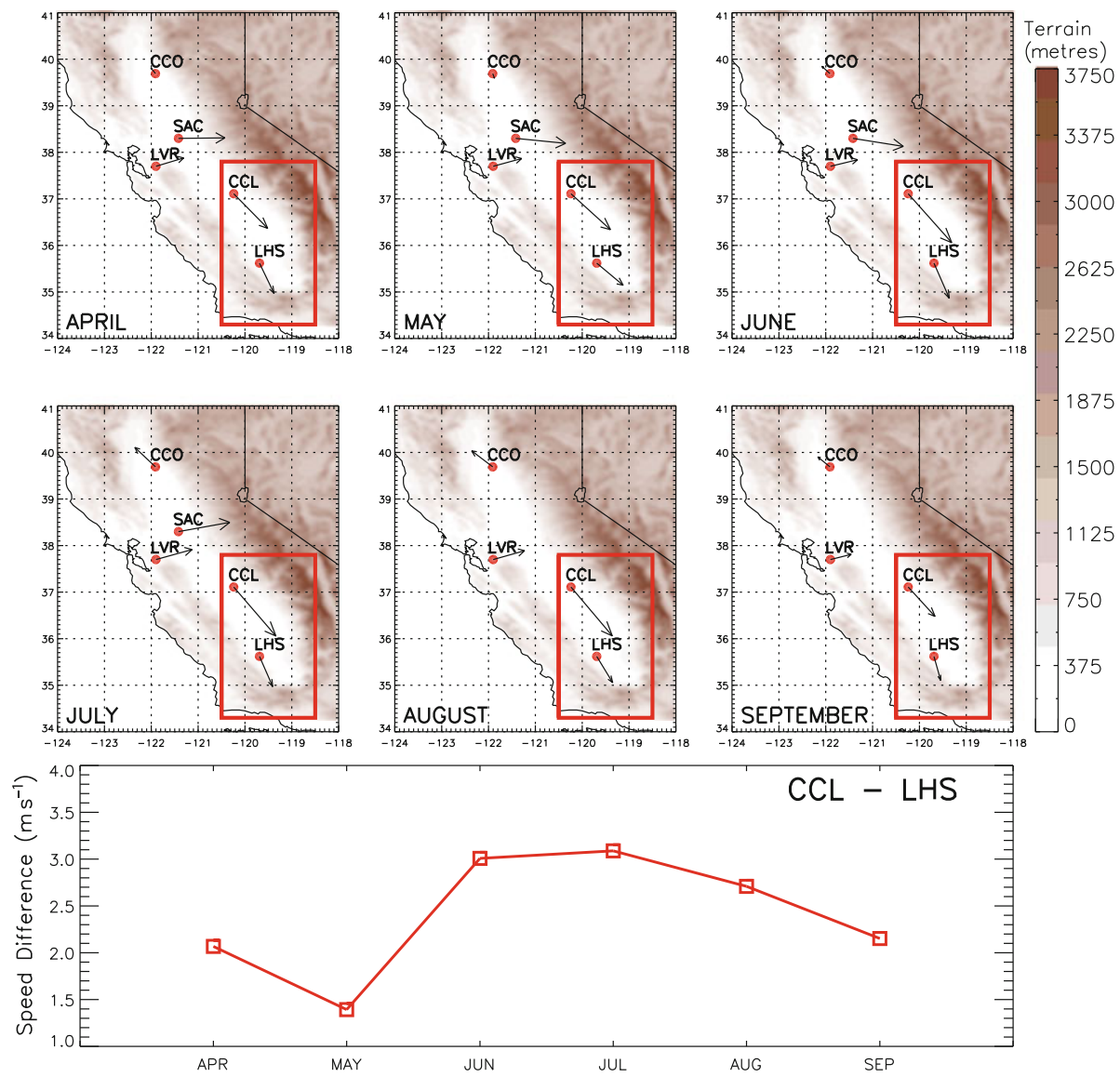

Fig. 10 Wind vectors for every site averaged for the six driest months from April to September over the first $500 \mathrm{~m}$ above the ground level

specific humidity is small, typically less than $5-10 \%$ of its monthly diurnal mean value. However, larger variations occur on a month-to-month basis, and this variation is investigated with Fig. 12, which shows the dependence of monthly-averaged maximum values of CBL depth on surface values of specific humidity for the six low-rainfall months of April to September. The correlation has the same pattern for all sites: low humidity and high CBL depths in the springtime months, and high humidity and low CBL depths in the summer months (especially July and August). All sites have a large negative correlation coefficients $r$, with values of $r=-0.92$ to -0.96 except for Lost Hills, which has a smaller value of -0.43 . The same correlation has been calculated using individual days in the six months from April to September, shown as red lines in Fig. 12 with correlation values indicated by red values in parentheses. A significant anti-correlation is still evident for all sites except Lost Hills. Lost Hills also has the lowest monthly mean humidities, especially for the summer months.

The lower humidity and lower correlation found at Lost Hills were investigated by comparing satellite images for the different sites (not shown). Satellite views of the sites of interest show, as described in Sect. 2.1, that Chico, Sacramento and Chowchilla are surrounded by 


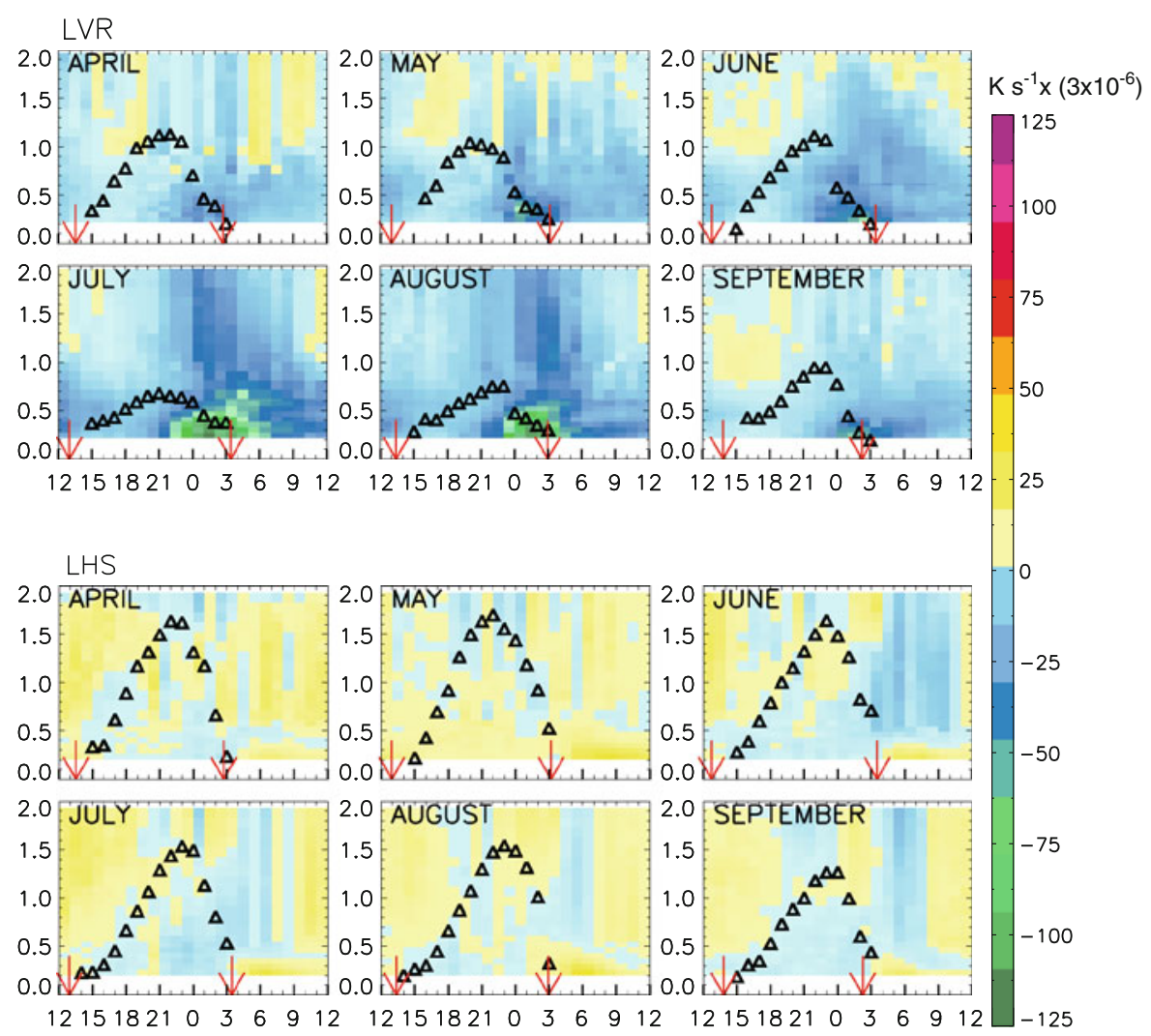

Fig. 11 Diurnal monthly mean time-height cross section of virtual temperature advection (colour) and CBL depth (black triangles), for the months from April to September, for Livermore (top panels) and Lost Hills (bottom panels). The $x$-axis is time (UTC); $y$-axis is the height $(\mathrm{km})$. Red arrows on the $x$-axis are the sunrise and sunset, respectively. The colour scale is $3 \times 10^{-6} \mathrm{~K} \mathrm{~s}^{-1}$

irrigated orchards and fields that dominate the land use of the area. Livermore is in a fairly heavily urbanized area; in contrast, the Lost Hills site is mostly surrounded by natural grass areas that dry out during the arid summer months. With less soil moisture, the surface heat flux (net available energy) will be expressed mainly as a sensible heat flux, which will drive convection, and therefore CBL growth. For the other sites, which are not as dry as Lost Hills, a larger fraction of the surface heat flux will be partitioned into the latent heat flux, with less sensible heat flux being available to drive convection. This will result in shallower CBL heights during the summer irrigation season.

\subsection{Synoptic-Scale Forcing}

To determine the role of synoptic meteorological forcing, monthly composite mean images of geopotential height and vertical velocity (omega) were computed using the National Center for Environmental Prediction/North American Regional Reanalysis (NCEP/NAAR) (Kalnay et al. 1996) dataset available at http://www.esrl.noaa.gov/psd/. The upper two panels of Fig. 13 are composite means of geopotential height $(\mathrm{m})$ for $850 \mathrm{hPa}$, averaged for the months 

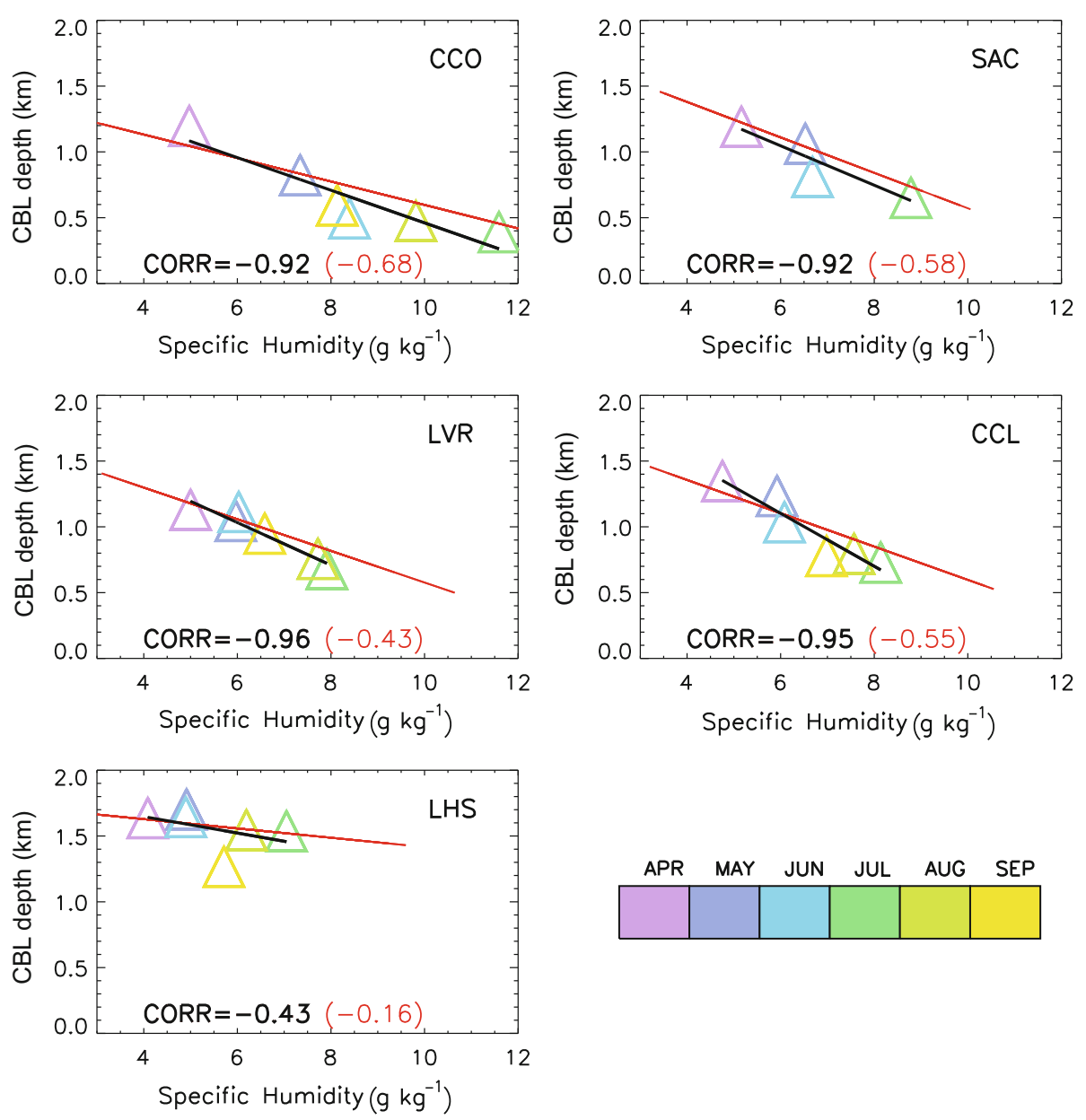

Fig. 12 Correlation between maximum values of boundary-layer depths ( $y$-axis) and surface values of specific humidity ( $x$-axis), using monthly-averaged data (coloured triangles and black lines), and daily data (red lines)

of April and May (left) and July and August (right). The lower two panels of Fig. 13 are composite means of omega $\left(\mathrm{Pa} \mathrm{s}^{-1}\right)$ for $850 \mathrm{hPa}$, averaged for the months of April and May (left) and July and August (right). The location of the five sites studied here is denoted with black stars. As can be seen in Fig. 13, the synoptic-scale flow at $850 \mathrm{hPa}$ is dominated by low pressure over the Great Basin to the east of California, resulting in north to northwesterly geostrophic flow over the study region, with only minor differences between the two seasons. The corresponding vertical motion at $850 \mathrm{hPa}$ shows subsidence over most of California in April-May, especially offshore and along the coast. In comparison, in JulyAugust both the percentage of the area with subsidence and the amplitude of the subsidence has decreased, with a larger part of the Central Valley showing rising motion. In particular, Chico, Sacramento and Chowchilla all show more negative values of omega in July-August, which would produce deeper CBL depths, not the shallower depths observed. However, the NARR does resolve the convergence and corresponding rising motion found previously in 
NCEP North American Regional Reanalysis Geopotential Height (m) Composite Meon

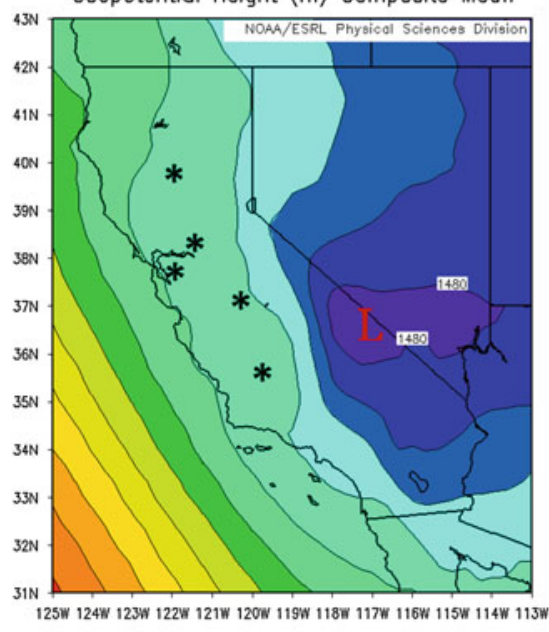

Apr 2008, May 2008

NCEP North American Regional Reanalysis Omega $\left(\mathrm{Pas}^{-1}\right)$ Composite Mean

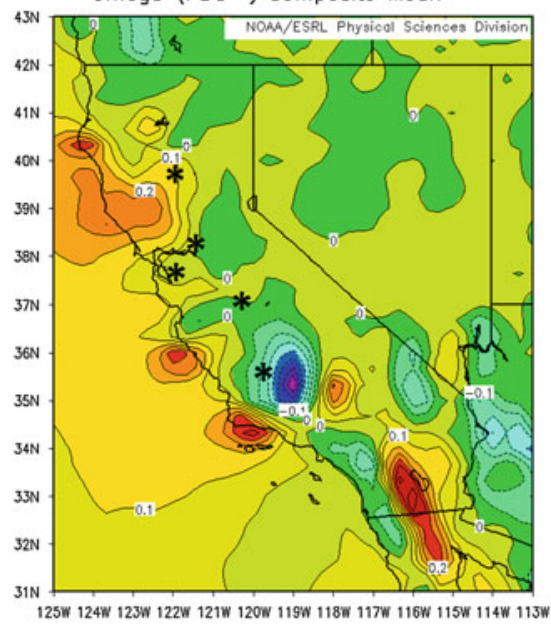

Apr 2008, May 2008
NCEP North American Regional Reanalysis

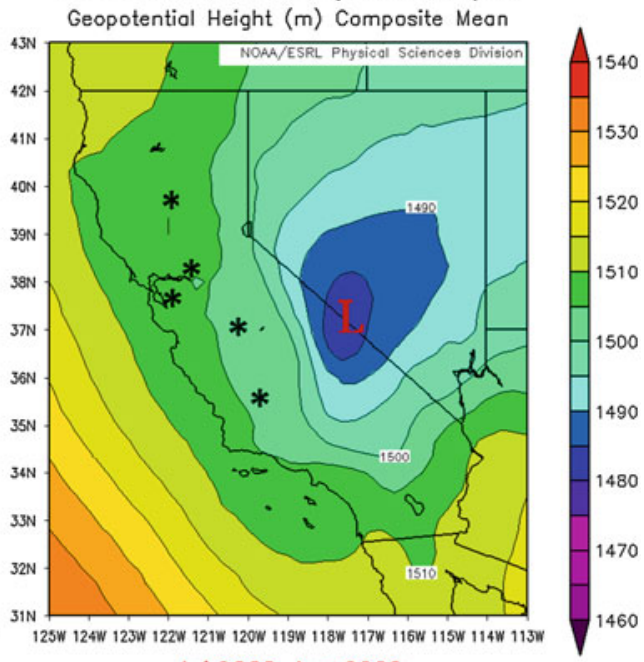

Jul 2008, Aug 2008

NCEP North American Regional Reanalysis Omega $\left(\mathrm{Pas}^{-1}\right)$ Composite Mean

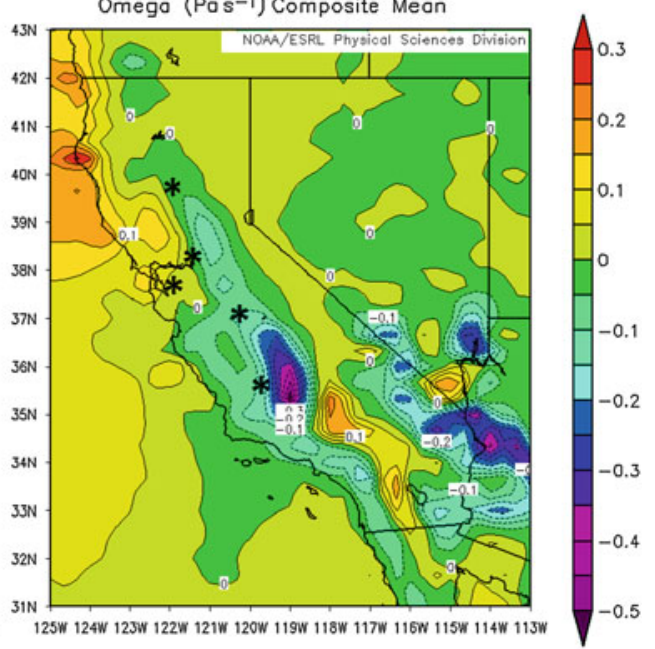

Jul 2008, Aug 2008

Fig. 13 NCEP/NARR Reanalysis. Upper panels 850-hPa geopotential height (m) composite mean averaged for the months of April and May (left), and July and August (right). Lower panels 850-hPa omega (Pa s ${ }^{-1}$ ) composite mean averaged for the months of April and May (left), and July and August (right)

the southern part of the San Joaquin Valley, which can help explain the greater CBL depths found at Lost Hills in both time periods.

\section{Summary and Conclusions}

In this study, we use a full year of observations to investigate the seasonal variation of boundary-layer structure, including CBL depth, wind speed and temperature. The observations 
were acquired by $915-\mathrm{MHz}$ radar wind profilers, associated radio acoustic sounding systems and surface sensors located at five different sites within California's Central Valley. We also investigate mechanisms that force or control CBL depth, including solar radiation, precipitation, lapse rate, mesoscale convergence, temperature advection, land-surface characteristics including irrigation patterns and synoptic-scale subsidence.

Monthly-averaged daily cycles of CBL depth together with the vertical distribution of the diurnal monthly-averaged wind speed at most sites show weaker winds within the CBL during the morning-to-early afternoon hours, and stronger winds associated with the presence of well-defined LLJs that begin to form in the late afternoon or early evening hours. Low-level jets are particularly visible during the late spring to early autumn, with monthly-averaged maximum jet speeds reaching up to $12 \mathrm{~m} \mathrm{~s}^{-1}$. The only site that did not have a significant LLJ is Livermore, where the flow is dominated by a late afternoon surge of marine air penetrating into the Central Valley.

The monthly-averaged daily cycle of CBL depth together with the vertical distribution of the virtual potential temperature shows that the highest CBL temperatures tend to occur after the maximum CBL depth is reached and that the decay of the CBL begins at as early as $3-5 \mathrm{~h}$ before sunset. Also, for all sites except Lost Hills, the warmest months from June to September did not have the deepest CBL depths.

A principal finding of our study is that, with the exception of Lost Hills, the CBL maximum depths are the greatest in the spring months, followed by a rapid decrease in the summer months. Surprisingly, maximum CBL depths at Livermore, Sacramento, Chico and Chowchilla are nearly the same in July as they are in December, approximately 600-700 m deep. The reduced CBL depths at these four sites is consistent with the low-level temperature lapse rates, with lapse rates larger in July than April, and larger than at the Lost Hills site in the southern San Joaquin Valley.

Mechanisms that could explain the unexpected behaviour of the summertime CBL depths were investigated in detail. Temporal and spatial variations in surface solar radiation and precipitation were ruled out as factors contributing to the shallow summertime CBL depths. Further analysis, however, suggested several reasons for the CBL depth behaviour. First, convergence of boundary-layer winds exists in the southern San Joaquin Valley near Lost Hills, with the strongest convergence during the months of June through August. This convergence occurs as the up-valley thermally driven flow decelerates when it reaches the mountain ranges at the end of the valley. It helps maintaining weaker lapse rates and greater boundary-layer depths at Lost Hills for the summer months when the convergence is greatest.

Second, the monthly-averaged temperature advection in the Delta Region between the Livermore site and Chico, Sacramento and Chowchilla reveals greater cold-air advection during the months of July and August compared to the temperature advection in the southern San Joaquin Valley between Chowchilla and Lost Hills. This enhanced cold-air advection is associated with the sea breeze and resulting cold marine inflow through the Delta Region and would contribute to the greater lapse rates found in the summer season in the Delta Region, which in turn will lead to shallower CBL depths.

A third possible explanation is due to land-use characteristics and irrigation patterns near the profiler sites. For the low-precipitation months between April and September, monthlyaveraged values of daily maximum CBL depths and monthly-averaged surface's specific humidity are strongly anti-correlated for all sites except Lost Hills. The Lost Hills site has the lowest monthly mean humidities, the lowest annual precipitation rate and less irrigation in the immediate vicinity of the site (as revealed by satellite images). For the other sites, higher specific humidity values found in the summer months could be because of an increase in irrigation. In this case, a greater part of the total surface heat is partitioned into the latent 
heat flux, with less sensible heat flux available to drive convection, resulting in shallower CBL heights. However, we note that the larger surface specific humidity values at the four more northern sites could also be due to a stronger influence of marine inflow. In addition, the smaller values of surface humidity found in the spring months and at the Lost Hills site could be interpreted to be as due to the greater CBL depths rather than their cause, as the surface moisture flux is mixed over a greater depth of the atmosphere, and as potentially more dry air aloft is entrained into the CBL.

Fourth, synoptic circulations revealed in the NCEP/NARR dataset do not indicate any significant increase in subsidence that could explain the shallow CBL depths at the four more northern sites during the summer months. However, the NARR does resolve the low-level convergence in the southern end of the San Joaquin Valley seen in the separate wind profiler observation analysis. This convergence is associated with the deceleration of up-valley flow as it reaches the higher elevation terrain at the end of the valley where it apparently is blocked. This upward motion persists from April to September and would facilitate the maintenance of large boundary-layer depths at Lost Hills for these months.

It is possible that other sub-NARR scale mountain valley circulations occur between the Central Valley and the Sierras and Coast Ranges, with rising motion on the mountain slopes and subsidence over the valley in between that would reduce CBL depths. Such a mountainvalley circulation could be enhanced in the summer months after the Sierra snowpack melts in May and June, and would then enhance the slope flow branch of the circulation and local subsidence over the valley. As it is difficult to ascertain the relative importance of the various forcing mechanisms from the observations alone, a numerical model-based analysis would be useful to confirm the mechanisms which this analysis has revealed and to quantify the results.

Direct measurements of boundary-layer depth are inherently difficult to make. Historically, boundary-layer depths are often estimated indirectly through measurements of related variables such as the vertical profile of potential temperature or the depth of an aerosol layer, which may or may not represent the true depth of the actively turbulent boundary-layer. Because of this difficulty, little information on the climatological variation of boundarylayer depth is available. This study has demonstrated that wind-profiling radars can provide a viable means of measuring high temporal resolution CBL depths on a routine basis. Networks of profilers can provide the information from which regional climatologies of CBL depths and their spatial variation can be derived. The annual variation of surface temperatures is strongly dependent on vertical mixing within the boundary layer, and if we are to have confidence in regional climate model predictions of temperature trends, then they must also be capable of predicting the annual variation in boundary-layer depth and structure. The unexpected behaviour of the CBL depth annual cycle in California, along with its strong modulation based on a likely combined effect of land use and topographically associated convergence and cold-air advection, makes it a good candidate to test the ability of regional climate models to accurately simulate boundary-layer processes.

\footnotetext{
Acknowledgements The authors wish to thank all engineers of the NOAA/ESRL/PSD2 group who take care of maintaining the operational functionality and availability of the data collected by the instruments located in three of the sites used in this study (Chico, Chowchilla and Lost Hills). For the Sacramento site, the authors offer their thanks to Ken Lashbrook from the Sacramento Metropolitan Air Quality Management District that provided us with the wind and temperature consensus files, and Charley Knoderer from Sonoma Technology Inc. that provided us with the wind-speed files. The authors thank the Bay Area Air Quality District administration that provided them with the profiler in Livermore. The authors also acknowledge that the surface data for Livermore and Sacramento sites were downloaded from the NCDC web site: http://www7. ncdc.noaa.gov/CDO/cdo, and the composite mean images that were provided by the NOAA/ESRL Physical Sciences Division, Boulder Colorado from their web site at http://www.esrl.noaa.gov/psd/. The authors also want to thank Paul Neiman for very helpful discussions.
} 
Open Access This article is distributed under the terms of the Creative Commons Attribution Noncommercial License which permits any noncommercial use, distribution, and reproduction in any medium, provided the original author(s) and source are credited.

\section{References}

Bao J-W, Michelson SA, Persson POG, Djalalova IV, Wilczak JM (2008) Observed and WRF-simulated lowlevel winds in a high-ozone episode during the Central California Ozone Study. J Appl Meteorol Climatol 47:2372-2394

Bianco L, Wilczak JM, White AB (2008) Convective boundary layer depth estimation from wind profilers: Statistical comparison between an automated algorithm and expert estimations. J Atmos Ocean Technol 25:1397-1413

Burk SD, Thompson WT (1996) The summertime low-level jet and marine boundary layer structure along the California coast. Mon Weather Rev 124:668-686

Endo S, Shinoda T, Tanaka H et al (2008) Characteristics of vertical circulation in the convective boundary layer over the Huaihe River Basin in China in the early summer of 2004. J Appl Meteorol Climatol 47:2911-2928

Frenzel CW (1962) Diurnal wind variations in central California. J Appl Meteorol 1:405-412

Hays TP, Kinney JK, Wheeler NJ (1984) California surface wind climatology. California Air Resources Board Rep., Sacramento, $180 \mathrm{pp}$

Kalnay E, Kanamitsu M, Kistler R, Collins W, Deaven D, Gandin L, Iredell M, Saha S, White G, Woollen J, Zhu Y, Leetmaa A, Reynolds R, Chelliah M, Ebisuzaki W, Higgins W, Janowiak J, Mo KC, Ropelewski C, Wang J, Jenne R, Joseph D (1996) The NCEP/NCAR reanalysis 40-year project. Bull Am Meteorol Soc 77:437-471

King JC, Argentini SA, Anderson PS (2006) Contrasts between the summertime surface energy balance and boundary layer structure at Dome C and Halley stations, Antarctica. J Geophys Res 111:Art. No. D02105, $13 \mathrm{pp}$

May PT, Strauch RG, Moran KP, Ecklund WI (1990) Temperature sounding by RASS with wind profiler radars-a preliminary study. IEEE Trans Geosci Remote Sens 28:19-28

Moore GE, Daly C, Liu M-K, Huang S-J (1987) Modeling of mountain-valley wind fields in the southern San Joaquin Valley California. J Clim Appl Meteorol 26:1230-1242

Ochs GR, Lawrence RS (1972) Temperature and $C_{n}^{2}$ profiles measured over land and ocean to $3 \mathrm{~km}$ above the surface. NOAA TR ERL 251-WPL 22, 39 pp

Schultz HB, Akesson NB, Yates WE (1961) The delayed 'sea breezes' in the Sacramento Valley and the resulting favorable conditions for application of pesticides. Bull Am Meteorol Soc 42:679-687

Stull RB (1988) An Introduction to boundary layer meteorology. Kluwer, Dordrecht, 670 pp

Tanaka H, Hiyama T, Yamamoto K et al. (2007) Surface flux and atmospheric boundary layer observations from the LAPS project over the middle stream of the Huaihe River basin in China. Hydrol Process 21:1997-2008

Wesely ML (1976) The combined effect of temperature and humidity fluctuations on refractive index. J Appl Meteorol 15:43-49

White AB (1993) Mixing depth detection using 915-MHz radar reflectivity data. Preprints, Eighth symposium on Observations and instrumentation. American Meteorological Society, Anaheim, pp 248-250

White AB, Fairall CW, Thomson DW (1991) Radar observations of humidity variability in and above the marine atmospheric boundary-layer. J Atmos Ocean Technol 8:639-658

Wilczak JM, Strauch RG, Ralph FM, Weber BL, Merritt DA, Jordan JR, Wolfe DE, Lewis LK, Wuertz DB, Gaynor JE, McLaughlin SA, Rogers RR, Riddle AC, Dye TS (1995) Contamination of wind profiler data by migrating birds-characteristics of corrupted data and potential solutions. J Atmos Ocean Technol 12:449-467

Wilczak JM, Gossard EE, Neff WD, Eberhard WL (1996) Ground-based remote sensing of the atmospheric boundary layer: 25 years of progress. Boundary-Layer Meteorol 78:321-349

Wyngaard JC, LeMone MA (1980) Behavior of the refractive index structure parameter in the entraining convective boundary layer. J Atmos Sci 37:1573-1585

Zaremba LL, Carroll JJ (1999) Summer wind flow regimes over the Sacramento Valley. J Appl Meteorol 38:1463-1473

Zhong SY, Whiteman CD, Bian XD (2004) Diurnal evolution of three-dimensional wind and temperature structure in California's Central Valley. J Appl Meteorol 43:1679-1699 